\title{
Does COVID-19 pandemic disrupt sustainable supply chain process? Covering some new global facts
}

\author{
Muhammad Khalid Anser ${ }^{1} \cdot$ Muhammad Azhar Khan ${ }^{2} \cdot$ Abdelmohsen A. Nassani $^{3}$. \\ Muhammad Moinuddin Qazi Abro ${ }^{3} \cdot$ Khalid Zaman $^{2} \cdot$ Ahmad Kabbani $^{4}$
}

Received: 5 July 2020 / Accepted: 7 June 2021 / Published online: 19 June 2021

(C) The Author(s), under exclusive licence to Springer-Verlag GmbH Germany, part of Springer Nature 2021

\begin{abstract}
The adverse effects of the coronavirus 2019 (COVID-19) pandemic are widely visible in the economic structure, while the principal causal factor is the disruption of the supply chain process that leads to the economies into a global depression. The purpose of the study is to identify the critical factors that affect the global sustainable supply chain process in the cross-sectional panel of 38 European countries, 14 North American countries, 40 Asian countries, and a heterogeneous panel of 111 countries. The results show that an increase in susceptible coronavirus cases and death tolls limits the supply chain process because of nationwide closures of industries and business activities. In contrast, an increase in the number of recovered cases supports economic activities and improved logistic performance index across countries. The innovation accounting matrix shows that since August 2020, the global coronavirus cases will decline and start resuming economic activities to increase the supply chain process. The result is further supported by the estimates of reduction in the proportion of death to recovered cases (case fatality ratio 1) to increase sustainable logistics activities. However, the supply chain process could affect an increasing death toll and case fatality ratio 2 (i.e., the proportion of death to registered cases) over time. The global economies should ensure a free flow of sustainable logistics supply, especially the supply of healthcare medical equipment that would help control the coronavirus pandemic, which escapes from the nations from a global depression.
\end{abstract}

Keywords Sustainable supply chain process $\cdot$ COVID-19 $\cdot$ Case fatality ratios $\cdot$ Regression analysis $\cdot$ Innovation accounting matrix

Responsible editor: Philippe Garrigues

Khalid Zaman

khalid_zaman786@yahoo.com

Muhammad Khalid Anser

mkhalidrao@xauat.edu.cn; khalidsnnu@yahoo.com

Abdelmohsen A. Nassani

Nassani@ksu.edu.sa

1 School of Public Administration, Xi'an University of Architecture and Technology, Xi'an 710000, China

2 Department of Economics, University of Haripur, Haripur, Khyber Pakhtunkhwa, Pakistan

3 Department of Management, College of Business Administration, King Saud University, P.O. Box 71115, Riyadh 11587, Saudi Arabia

4 Department of Management, Aleppo University, Aleppo, Syria

\section{Introduction}

The natural catastrophic event faced by the global world started in late December 2019, when the emergence of the infectious disease called SARS-CoV-2 (severe acute respiratory syndrome coronavirus 2) affected initially few people in the Wuhan city of China that comes with breathing problem and those affected are admitted to the hospital; then, this virus spread in a significantly shorter period in the country and it triggered around the globe (He et al. 2020). The WHO declared this pandemic as a global emergency and moved forward to contain this virus with asymptomatic treatment. Later, it has been confirmed that the pandemic is untreatable, and it is spreading through a droplet from coughing, sneezing, touching, and talking, and through close contacts (Purcell and Charles 2020). This situation is cumbersome, and the countries followed the instructions of WHO guidelines, restricting people from close contact and maintaining social distancing. Furthermore, the economies cease their borders, restrict 
domestic and international flights, and close non-essential industries and businesses, restricting people, children, and students in their homes, and nationwide lockdown (WHO 2020). It has carried out all these activities briefly; thus, it creates many socio-economic and environmental issues, which depress the countries across the globe. The healthcare infrastructure, a number of physicians, paramedical staff, and other essential services remain open and confront the epidemic with solicited strategies (Ahmed et al. 2020). The supply chain process is primarily affected, especially the healthcare supply chain that is at the forefront with the problem. The global income goes down (Nicola et al. 2020), unemployment increases (Kawohl and Nordt 2020), food security challenges (Glauber et al. 2020) and risks of global poverty increase (Anser et al. 2020a), and financial crisis (Goodell 2020), environmental challenges (Lai et al. 2020), healthcare issues (Greenberg et al. 2020), and many other uncontrolled factors burst that negatively affect economies and their community members. The COVID-19 measures to contain the epidemic further pressure business industries and logistics supply that increase global depression. The time to cope with the coronavirus pandemic is the most formidable challenge the global world faces that needs unified global policies to overcome the epidemic's issues (Liu et al. 2020; Ivanov and Dolgui 2020).

The study used the logistics performance index (LPI) as a substitute for the supply chain process. Generally, the supply chain management system starts from delivering a product from raw material to the end user, while LPI is used to deliver a product from the customs clearance process to shipment. Thus, the term LPI is used here for an interchangeable word with the supply chain process in a more purified way. In search of the literature on COVID-19 and supply chain disruptions, the study found the following statistical numbers related to scholarly writing in a given topic. The study used the following keywords and Boolean operators to assess the number of scholarly writings available on the given topicthe Google Search engine was used for this purpose which is conducted on May 29, 2020. The "first keyword" is written in general search (anywhere in the article), i.e., "COVID-19" AND "Supply Chain"; the Google Search shows 3390 results in $0.21 \mathrm{~s}$. The study substitutes the search title, i.e., "Coronavirus" AND "Supply Chain"; the Google Search has given 1990 results in just $0.13 \mathrm{~s}$. The study now replaced "supply chain" with "logistics" as both are used as interchangeable words to some extent. The Google Search shows 2510 results in just $0.13 \mathrm{~s}$, while when we used the keyword, i.e., "Coronavirus" AND "Logistics," the results show 1820 in just $0.11 \mathrm{~s}$. For more clear visibility, the study shows these statistics in Fig. 1 for ready reference.

The work is extensively available on the stated theme. For a closer look, the study searched the given keywords "in the title of the articles." This way gives more analytical wisdom to understand the current work available on the given theme.
The following information has been obtained through the given search, presented in Table 1 for ready reference.

Based on given statistics, we used "COVID-19" AND "Supply Chain" in the study's title to give more insights for future scholars to get benefit from this work to proceed further for global prosperity.

The study framed the following research questions that further interlinked with the study's research objectives, i.e., To what extent sustainable supply chain process is affected by the COVID-19 pandemic? The different COVID-19 factors have been identified to assess their potential impacts on logistics supply across a heterogeneous panel of countries. Secondly, does an increase in COVID-19 cases and death toll substantially decrease sustainable supply chain activities across countries? The need for careful assessment is required, as the higher registered cases and death toll required urgent need of free flow of healthcare supply chain to provide safeguard to the healthcare physicians and the suspected patients worldwide. Finally, does an increase in case fatality ratio and high recovery of the coronavirus patients may increase and decrease global supply chain activities, respectively? These three research questions reasonably indicate the disruption of the logistics supply chain during the pandemic recession. COVID-19 was confirmed to infect individuals while affecting the economies at the socio-economic and environmental forum, based on increasing out-of-pocket healthcare expenditures, lower transportation mobility, and depressing immune system because of pollution.

The greater need to use sustainable logistics operations to contain the coronavirus pandemic and environmental issues is pivotal for long-term growth worldwide. These research questions required fair statistical analysis to analyze the relationship between the stated variables across countries.

\section{Purpose, research contributions, and objectives of the study}

The study aims to critically analyze the impact of the COVID19 pandemic on the global logistics supply chain. The COVID-19 pandemic disrupted the supply chain in many ways, as due to strict lockdown in many countries, transportation logistics activities were largely disordered that affected the healthcare supply chain and other essential transportation goods. Furthermore, the efficiency of the customs clearance process, quality of trade infrastructure, international shipments, customs brokers, tracking assignments, and timeliness of shipment activities have all been disrupted mainly due to COVID-19 prevention measures on a global scale. Thus, this study used the comprehensive measure of overall logistics supply that covered all the stated aspects of the logistics supply indices for a large cross-sectional panel of countries. The earlier studies were limited to the use of few sub-logistics indices in relation with COVID-19 pandemic that merely 
Fig. 1 Google Search results (anywhere in the title). Source: Google Search

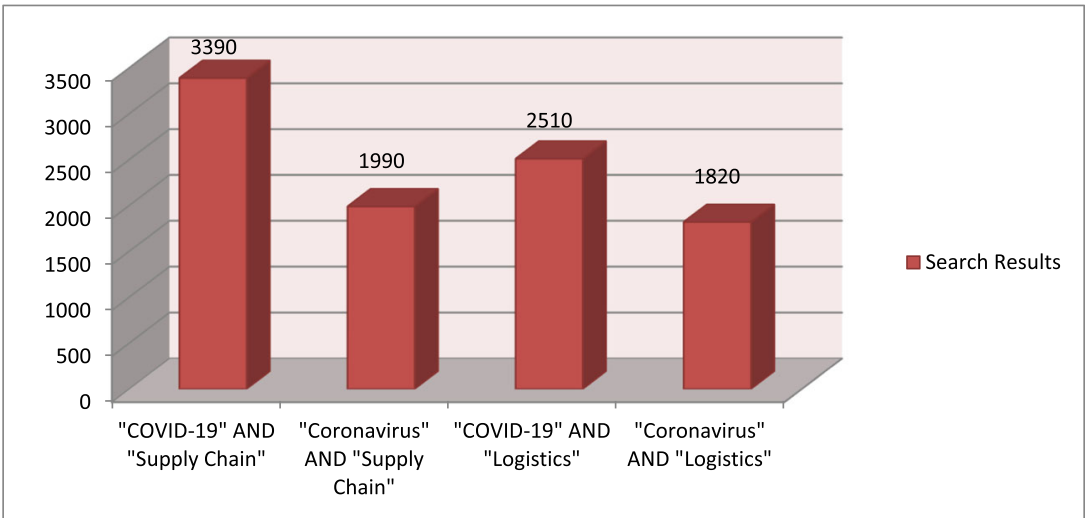

shows the picture of one side of the coin (Yu et al. 2020; El Baz and Ruel 2021). On the other side, the earlier studies used different datasets of COVID-19-infected cases, recovered cases, and death cases as a regressor to assess their negative effect on the country's socio-economic and environmental settings (Anser et al. 2020b, 2020c; Gagliano et al. 2020; Loske 2020), while a little work is available that used different case fatality ratios as a regressor to assess their impact on logistics activities, which is used in this study to fill the literature gap that gives new insights of the results to cover new global facts. The following research objectives have been made in a given scenario, i.e.:

i.) To examine the impact of an increase in coronavirus cases and its death toll on disruption in the sustainable supply chain process across different world regions and panel of countries

ii.) To estimate the case fatality ratio and analyzed its impact on the global logistics performance index

iii.) To analyze the relationship between recovered coronavirus patients and supply chain processes across countries

These objectives need empirical analysis to answer the stated research questions, and it would make them helpful to propose sound policy inferences to managing the global healthcare infrastructure. The study's organization consists of seven different sections, including the "Introduction"

Table 1 Google Search results (in the title of the article)

\begin{tabular}{lll}
\hline Keywords & Search results & Search time (s) \\
\hline "COVID-19" AND "Supply Chain" & 13 & 0.13 \\
"Coronavirus" AND "Supply Chain" & 4 & 0.06 \\
"COVID-19" AND "Logistics" & 4 & 0.21 \\
"Coronavirus" AND "Logistics" & Nil & Nil \\
Total & 21 & 0.40 \\
\hline
\end{tabular}

Source: Google Search section which presented the introduction of the study. The "Literature review" section shows the literature review. The "Data source and methodological framework" section presented the data source and methodological framework. The "Results" section shows the results. The "Discussion of findings" section discussed the findings. The "Conclusions" section shows conclusions, and the "Policy recommendations" section shows policy implications.

\section{Literature review}

The little work is available directly on the stated theme. Hence, the study includes all relevant scholarly works in this section for worthy discussion. Galaitsi et al. (2021) discussed different system performance concepts that interchange use in the wide variety in characterizing the systems facing threats, including agility, resilience, and sustainability. Agility helps to understand the system risks and able to perform quickly and easily. On the other front, resilience can recover quickly from system threats, while sustainability is the course of action that can maintain the risk at a certain level. Thus, these concepts are more likely different to understand the system threats to minimize the risk. Ivanov (2020a) discussed the viability of an effective supply chain (VSC) process into three main dimensions, i.e., agility, resilience, and sustainability. Agility is the main prospect that shows the quickness and suppleness of the supply chain process, while resilience and sustainability are related to the flexibility of the supply chain and the ability to exist to meet future demands continually. The study argued that the VSC elements could meet the pre- and post-COVID19 pandemic challenges, while resilience is the central factor that guarantees the VSC process to meet the future logistics challenges across the globe. The sustainability in logistics activities needs to be defined for an effective supply chain. Golan et al. (2020) conducted a systematic literature review on supply chain viability. They found a severe lack of "resilience" in the supply chain process, while this inflexibility is further shown during the emergence of the COVID-19 
pandemic, which negatively affects the logistics operations across the globe. The effective supply chain process would be better performed under consideration of sustainable operations worldwide. Mahajan and Tomar (2020) considered a case study of the Indian economy and examined the food supply chains during the COVID-19 pandemic and found that the limited supply chain process mainly decreases vegetables, edible oils, and fruit supply. The few more reasons associated with the limited food supply chain, e.g., the area of production zones beyond the retailer centers, fall the food supply availability across cities. Agrawal et al. 2020) confirmed their findings for the Indian economy in the supply chain process perspectives that were severely affected by nationwide lockdown, which triggered the economy into depression. Novak and Loy (2020) argued that due to the coronavirus pandemic, the large scale of outbreak limited the economic activities, which leads to geographical and political lockdown that disrupts the supply chain process worldwide. The healthcare supply chain should be vigilant and resilient to ensure supply and production from the starting point to the end destination. Goel et al. (2020) discussed the viability of the supply chain process in global economic growth in terms of increasing investment scenario, labor quality, and labor supply; however, the emergence of SARS-CoV-2 disrupts the supply chain process and decreases global income, which increases mass panic in the global world. Larrañeta et al. (2020) emphasized the need to use three-dimensional printing to ensure the supply of medical devices and personal protective equipment in hospitals and homes. Rowan and Laffey (2020) argued that it is high time to manage supply chain activities, especially healthcare equipment, including ensuring the free supply of personal and protective equipment (PPE) to safeguard our healthcare workers fighting against the coronavirus pandemic. The reprocessing of PPE is also deemed desirable to minimize the deficiency of PPE items by adopting most sterilization technologies. The use of UV irradiation and vaporized hydrogen peroxide could be more useful for the PPE process. Linkov et al. (2020) argued that value chain analyses help build a competitive business model to prevent any unwanted external shocks that negatively impact business activities. The few more scholarly writings available on COVID-19 and its effect on logistics performance and value chain are those of Bandyopadhyay (2020), Villalobos-Arias (2020), Gagliano et al. 2020), and Rosenbaum (2020); all these studies discussed mainly the logistic analytics and healthcare issues about the COVID-19 pandemic and emphasized the need to ensure healthcare supplies items in order to reduced coronavirus-associated death toll across countries.

The dynamic capability theory and innovation capacity theory of the supply chain shows their importance to improving logistics operations by competitiveness and integrated policies to minimize any specific internal and external shocks (Wong et al. 2020). The spread of the COVID-19 pandemic mainly disrupts the supply chain process and its logistics operations that need to be stabilized through organizations' dynamic capabilities and inventory management strategy for long-term growth (Al-Mansour and Al-Ajmi 2020). Based on the stated theories, the study proposed the following research hypotheses that are helpful for devising policy formulations, i.e.:

H1: The likelihood that increasing coronavirus registered cases and death toll disrupts the supply chain process. $\mathrm{H} 2$ : The lower case fatality ratios will allow beginning logistics activities worldwide.

H3: The high rate of coronavirus recovered cases will allow making smart lockdown strategy to support business activities.

These hypotheses need to be checked by using sophisticated statistical techniques for getting robust findings.

\section{Practical and theoretical contributions of the study}

The study contributed both fronts of practical and theoretical viewpoints. The study's practical contribution is to link statistical results with the academician viewpoints through asking questions. The five questions were designed to get views of academicians regarding the pandemic recession and sustainable logistics supply and interlink it with the statistical results. On the other hand, the study theoretically contributes to the earlier studies by extending the resource-based view and dynamic capability of the supply chain process to prevent it from some exogenous shocks, specifically from the coronavirus pandemic. This study is pragmatic and helpful in exerting some new global facts related to the COVID-19 recession and sustainable logistics supply worldwide.

\section{Data source and methodological framework}

The study used the following variables to analyze the impact of COVID-19 on supply chain disruption: total cases (denoted by CAS), total death (denoted by DTH), and total recovered cases (dented by RECOV) served as proxy variables for analyzing the COVID-19 pandemic across the globe. The data is taken from Worldometer (2020, May 29). The case fatality ratio is calculated based on the above data in two forms, i.e., case fatality ratio - death to total cases (denoted by CFRD1), and case fatality ratio - death to total recovered cases (denoted by CFRD2). Finally, the overall logistics performance index (denoted by LPI) $(1=$ low to $5=$ high value $)$ is used to assess sustainable supply chain activities worldwide. The data is taken from the World Bank (2020). The study used crosssectional data of COVID-19 factors at a specific date, i.e., May 29, 2020. The annual LPI data of 2018 is used to 
compute the disruption of supply chain process with the COVID-19 pandemic in four different cross-sectionals, i.e., (i) the study collected data from 111 countries primarily affected by the COVID-19 pandemic in terms of increasing registered cases and the death toll at one point in time, (ii) the study considered a cross-sectional data of 38 European countries, (iii) the data of 14 North American countries are also used in the study, and (iv) finally the study used 40 Asian countries in the analysis for more robust inferences. The daily data of COVID-19 registered cases, recovered, and death cases are regularly updated and collected from the Worldometer (2020) database, while the LPI dataset is collected by the World Bank and reported in the World Development Indicators on an annual basis. Thus, both data are combined to estimate the parameter of interest. Table 2 shows the sample of countries used in the study for ready reference.

The choice of countries' selection based upon high COVID-19 cases and overall logistics supply chain portfolio helps to understand the vulnerability of the COVID-19 pandemic on supply chain process. The study extended the

Table 2 List of countries

Panel of 111 countries: USA, Brazil, Russia, Spain, UK, Italy, France, Germany, India, Turkey, Iran, Peru, Canada, Chile, China, Mexico, Saudi Arabia, Pakistan, Belgium, Qatar, Netherlands, Bangladesh, Belarus, Ecuador, Sweden, Singapore, UAE, Portugal, Switzerland, South Africa, Colombia, Ireland, Indonesia, Kuwait, Poland, Ukraine, Egypt, Romania, Japan, Austria, Dominican Republic, Philippines, Argentina, Afghanistan, Panama, S. Korea, Serbia, Bahrain, Kazakhstan, Czech Republic, Oman, Algeria, Nigeria, Bolivia, Armenia, Moldova, Morocco, Malaysia, Ghana, Australia, Finland, Iraq, Cameroon, Honduras, Guatemala, Sudan, Luxembourg, Hungary, Tajikistan, Guinea, Uzbekistan, Senegal, Thailand, Djibouti, Greece, Bulgaria, Bosnia and Herzegovina, Gabon, Croatia, El Salvador, North Macedonia, Cuba, Estonia, Somalia, Iceland, Lithuania, Kenya, Kyrgyzstan, Sri Lanka, Slovakia, Maldives, New Zealand, Slovenia, Haiti, Venezuela, Mali, Lebanon, Albania, Tunisia, Hong Kong, Latvia, Zambia, Equatorial Guinea, Nepal, Costa Rica, Niger, Cyprus, Paraguay, Burkina Faso, Sierra Leone, and Uruguay

Europe -38 countries: Russia, Spain, UK, Italy, France, Germany, Belgium, Netherlands, Belarus, Sweden, Portugal, Switzerland, Ireland, Poland, Ukraine, Romania, Austria, Serbia, Czech Republic, Norway, Moldova, Finland, Luxembourg, Hungary, Greece, Bulgaria, Bosnia and Herzegovina, Croatia, North Macedonia, Estonia, Iceland, Lithuania, Slovakia, Slovenia, Albania, Latvia, Malta, and Montenegro

North America-14 countries: USA, Canada, Mexico, Dominican Republic, Panama, Honduras, Guatemala, El Salvador, Cuba, Haiti, Costa Rica, Jamaica, Trinidad and Tobago, and Bahamas

Asia-40 countries: India, Turkey, Iran, China, Saudi Arabia, Pakistan, Qatar, Bangladesh, Singapore, UAE, Indonesia, Kuwait, Japan, Philippines, Afghanistan, S. Korea, Bahrain, Kazakhstan, Oman, Armenia, Malaysia, Iraq, Tajikistan, Uzbekistan, Thailand, Kyrgyzstan, Sri Lanka, Maldives, Lebanon, Hong Kong, Nepal, Cyprus, Georgia, Jordan, Vietnam, Yemen, Mongolia, Brunei, Cambodia, and Bhutan

Source: Worldometer (2020) theoretical framework from the scholarly work of El Baz and Ruel (2021) that focused on supply chain risk management in the era of the COVID-19 pandemic. The resourcebased view in an organizational setting has a particular place, where the firms prepare to any shocks to mitigate it by its available resource base, including physical, human capital, and organizational resources (Nandi et al. 2020). For this purpose, the firms need dynamic capabilities to respond to the specified issues through integration and reconfigure their internal and external skills to move forward in the challenging environment ( $\mathrm{Vu}$ 2020). Furthermore, the need to quip it with information and communication technologies helps the firms reduce the supply chain disruptions due to any economic plague (McMaster et al. 2020). The information processing theory supports building new ideas and capabilities to improve the logistics chain to contain the COVID-19 pandemic through digitalize functioning process (Yang et al. 2020; Queiroz et al. 2020). Based on the stated discussion, the study used the following empirical equation used to analyze the vulnerability of the COVID-19 pandemic on supply chain management across countries, i.e.:

$$
\begin{aligned}
L P I_{i t}= & \vartheta_{0}+\vartheta_{1} C A S_{i t}+\vartheta_{2} D_{T H}+\vartheta_{3} R E C O V_{i t} \\
& +\vartheta_{4} C F R D 1_{i t}+\vartheta_{5} C F R D 2_{i t}+\varepsilon_{i t} \therefore \frac{\partial C A S}{\partial L P I} \\
< & 0, \frac{\partial D T H}{\partial L P I}+<0, \frac{\partial R E C O V}{\partial L P I}>0, \frac{\partial C F R D 1}{\partial L P I} \\
< & 0, \frac{\partial C F R D 2}{\partial L P I}<0
\end{aligned}
$$

where LPI shows logistics performance index; CAS shows total cases; DTH shows total death; RECOV shows total recovered; CFRD1 shows case fatality ratio - death to cases; CFRD2 shows case fatality ratio - death to recovered cases; it shows countries and time period; and shows error term.

Equation (1) shows that LPI is expected to be decreased by increasing COVID-19 registered cases and death tolls, while high recovered cases would likely increase it. The case fatality ratio 1 and 2 both will negatively affect supply chain activities

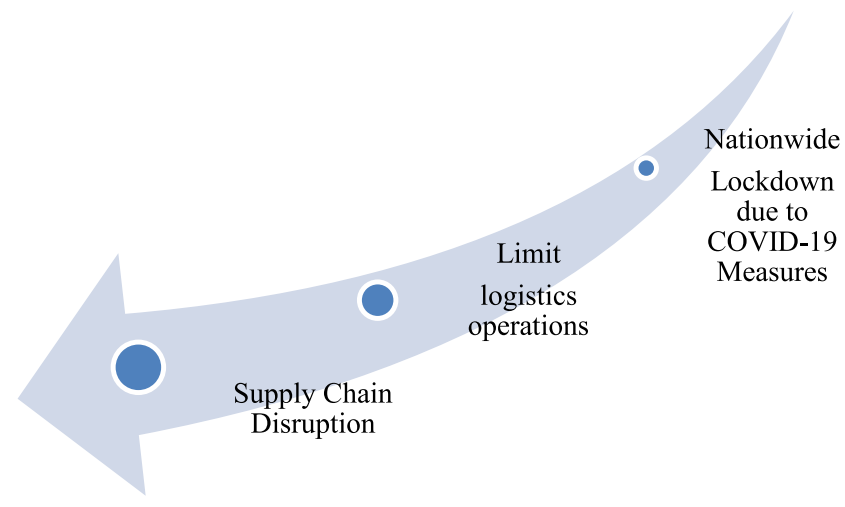

Fig. 2 Research framework. Source: Authors' extraction 
across countries. Figure 2 shows the research framework of the study for ready reference.

Figure 2 shows that COVID-19 pandemic measures to control death toll and reduce case fatality ratio are possible due to social distancing between the community members. The nationwide lockdown is one of the series to contain coronavirus; however, it has been associated with some socio-economic and environmental issues that negatively affect the global economy's growth. The disruption of the supply chain process is one of the adverse outcomes of COVID-19 measures that limit logistics operations worldwide, which cause a novel global depression.

The study used threshold regression and multiple regression techniques to analyze the relationship between the stated variables at varying worldwide countries, including selected countries of Europe, North America, Asia, and the rest of the countries' panel. Furthermore, the study used an innovation accounting matrix to assess monthly future progression in the supply chain process in the worldwide dataset. The importance of the stated methods in economic estimations is a wide variety in nature. The threshold regression models give a unique estimation of inferences on different change points. Its procedure is simple but more logical to get the smooth relationship between the regressand and regressors. Threshold regression usually forms four basic types of threshold effects: (i) step point, (ii) hinge point, (iii) segmented point, and (iv) stegmented point. The first two types of threshold effects are common in nature, identified at zero slopes before the change point, while the latter two types allow non-zero slope between the change points. Additionally, the stegmented model synthesizes the "step" point and "segmented points" together. Figure 3 shows the elaboration of the different types of threshold regression for ready reference.

\section{Results}

Table 3 shows the trend analysis of candidate variables for ready reference. The maximum count of total registered cases, death tolls, and recovered cases on May 29, 2020, is about $1,768,461,103,330$, and 498,725 , with a mean value of 50,639.31, 2902.018, and 23,199.42, respectively. The average value of "case fatality ratio - death to registered cases" and "case fatality ratio - death to recovered cases" is about 3.682 and 10.481 , respectively, while the mean index value of LPI is 2.981 with a maximum value of 4.20 and a minimum value of 1.950. The lower mean value of LPI and high COVID-19 cases clearly show that the coronavirus pandemic disrupts supply chain process worldwide.

Table 4 shows the threshold regression estimates in 111 countries, 38 European countries, 14 North American countries, and 40 Asian countries. The results show that higher coronavirus cases lead to decreased logistics performance index in the heterogeneous panel of countries and European panels, while higher death toll further decreases supply chain process in the North American panel of countries. The increased recovery rate tends to relax nationwide lockdown, and nations subsequently used a smart lockdown strategy that supports business activities and logistics operations. Although unable to signify their impacts on logistics operations, the case fatality ratios further are assessed in an inter-temporal framework in subsequent sections. The results are consistent with the earlier studies in different economic settings; for instance, Ivanov (2020b) predicted the COVID-19 impacts on the global supply chain process and confirmed the long-term disruption of logistics activities globally. Stephenson (2020) stressed the need to ensure the supply of critical healthcare logistics that badly suffered due the COVID-19 pandemic and its measures. The outbreak of coronavirus 19 from China to the rest of the world leads to a severe deficiency of critical healthcare instruments to the USA and the other world. The US-FDA regulatory body emphasized ensuring the supply of critical medical instruments and products and contacting different medical and surgical manufacturers to do contingency planning for supplying a free flow of medical gadgets to the USA. Malhotra (2020) confined its finding on managing agricultural supply chains affected by the COVID-19 pandemic. The harvesting of crops and post-harvesting operations need a stable agricultural supply chain to gain agricultural productivity to minimize economic losses. Iyengar et al. (2020) argued that the emergence of COVID-19 across the world leads to severe issues of managing public health crises, including logistics supply of healthcare devices, surgical equipment, and medical products. There is a greater need to ensure a free flow of logistics supply and production of medical and healthcare products in order to meet the challenges of the healthcare crisis across the globe.

The statistical tests confirmed the goodness-of-fit and model stability of the model. The diagnostic tests confirmed that the model is free from normality, serial correlation, and heteroskedasticity issues. The CUSUM and square of CUSUM test further verify the model stability in the different panel of countries. Figure 4 shows the recursive coefficients of the given variables and found that the given parameters fall in the critical zone of $5 \%$ confidence interval; thus, the parameter estimates are stable over time.

Table 5 shows the impulse response function of LPI, as logistics index mainly affected by the COVID-19 pandemic. The result is assumed on monthly basis variations that take total registered cases, death tolls, and recovered cases. The forecast estimates show that from June 2020 to August 2020 , there is an expected increase of coronavirus cases that limit supply chain activities, while after September 2020, the high rate of recovered cases and reduced registered coronavirus cases tend to increase logistics performance index, which eventually led to improve supply chain activities. It will begin 


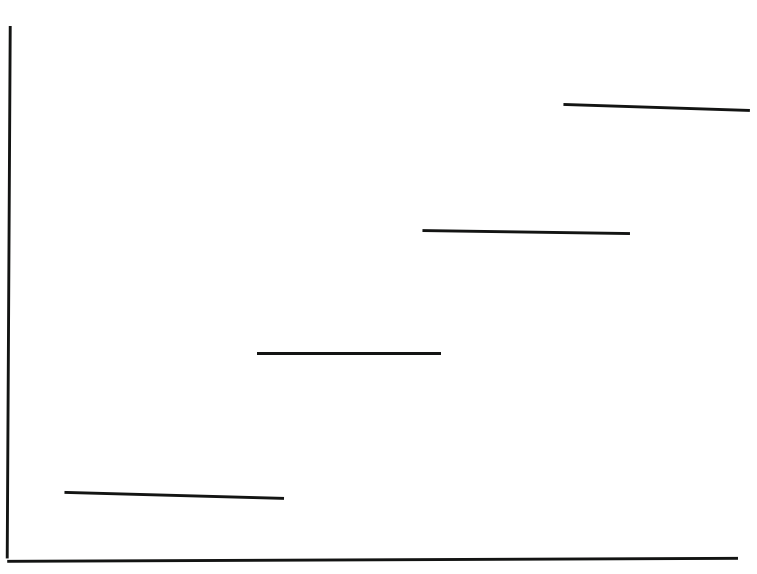

a

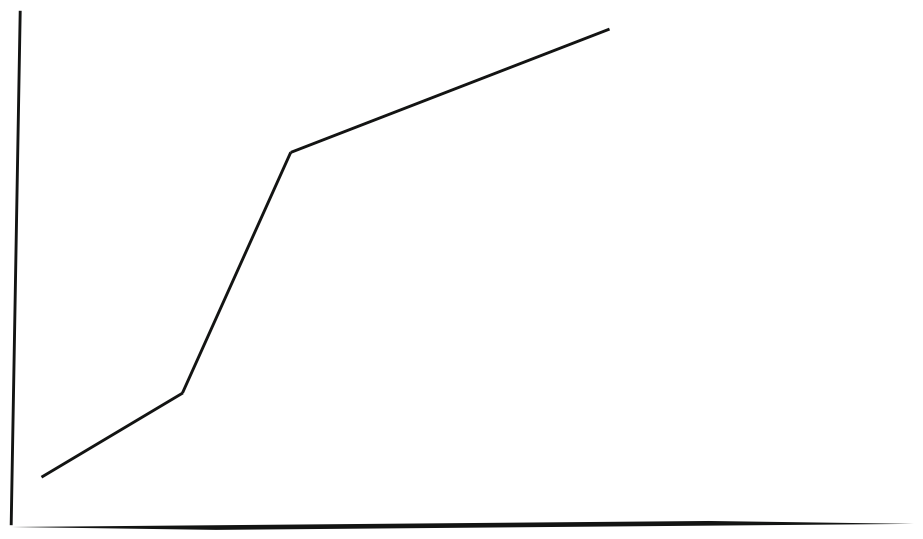

C

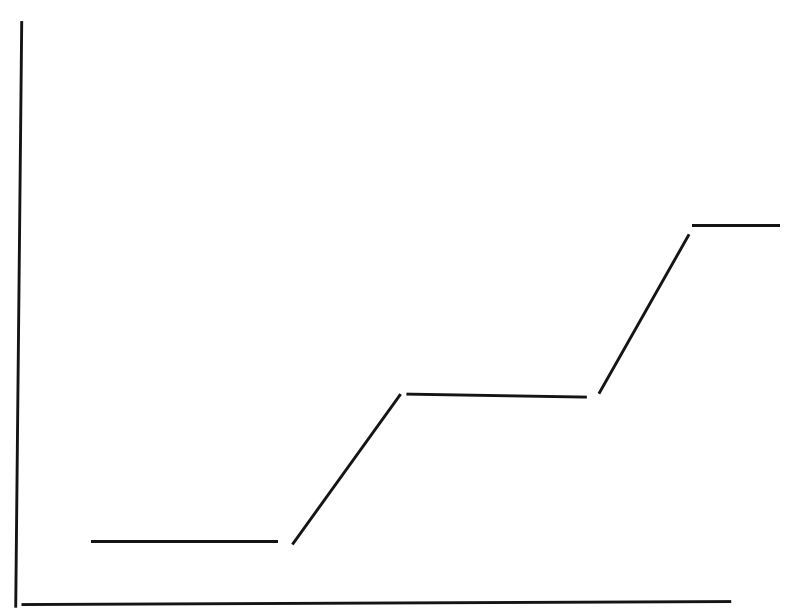

b

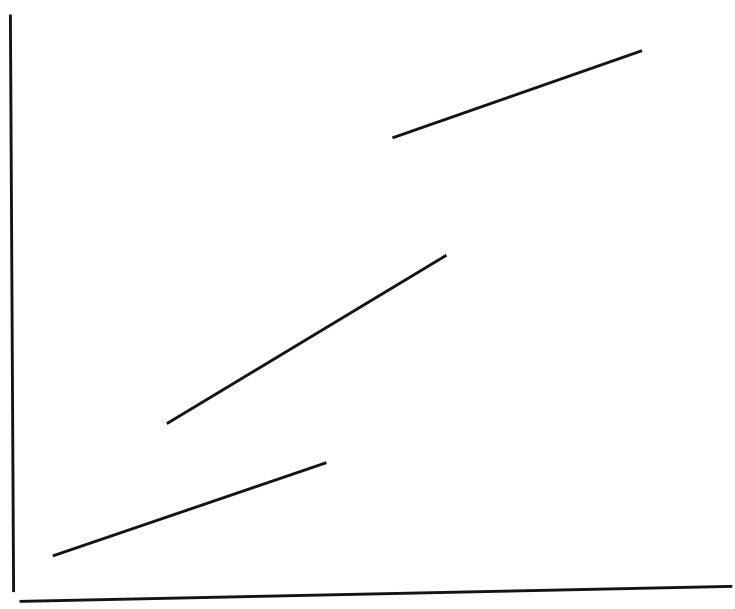

d

Fig. 3 Different types of threshold effects. a Step point effect. b Hinge point effect. c Segmented point effect. d Stegmented point effect. Source: Adapted from Fong et al. (2017)

to resume operational activities. Although it is expected that sensitive coronavirus cases will substantially decrease from August 2020 to February 2021, the death tolls may hinder supply chain activities across countries. The proportion of death to registered coronavirus cases will begin to decline logistics activities, while the proportion of death to recovered

Table 3 Descriptive statistics

\begin{tabular}{llllll}
\hline Methods & CAS & DTH & RECOV & CFRD1 & CFRD2 \\
\hline Mean & $50,639.31$ & 2902.018 & $23,199.42$ & 3.682 & 10.481 \\
Maximum & $1,768,461$ & 103,330 & 498,725 & 16.228 & 159.090 \\
Minimum & 811 & 4 & 22 & 0.064 & 0.125 \\
Std. Dev. & $181,161.9$ & $11,233.60$ & $60,948.21$ & 3.281 & 18.827 \\
Skewness & 8.110 & 7.116 & 5.182 & 1.688 & 5.435 \\
Kurtosis & 75.89 & 60.839 & 36.570 & 6.315 & 39.338 \\
Countries & 111 & 111 & 111 & 111 & 0.562 \\
\hline
\end{tabular}

CAS shows total registered cases, DTH shows total death, RECOV shows total recovered, CFRD1 shows case fatality ratio concerning death to total cases, CFRD2 shows case fatality ratio concerning death to recovered cases, and LPI shows logistics performance index 
Table 4 Threshold regression analysis

\begin{tabular}{lllll}
\hline Variables & Panel of 111 countries & Europe & North America ${ }^{\text {a }}$ & South Asia \\
\hline Constant & $2.586^{*}$ & $2.806^{*}$ & $2.481^{*}$ & $2.563^{*}$ \\
CAS & $-4.78 \mathrm{E}-05^{*}$ & $-8.19 \mathrm{E}-05^{*}$ & $6.88 \mathrm{E}-06$ & $-2.52 \mathrm{E}-05$ \\
DTH & ----- & ---- & $-0.0005^{* *}$ & ---- \\
RECOV & $0.00016^{*}$ & $0.00018^{*}$ & $8.42 \mathrm{E}-05^{*}$ & $0.00012^{*}$ \\
CFRD1 & 0.024 & 0.016 & -0.0002 & 0.054 \\
CFRD2 & -0.0035 & 0.011 & -0.0019 & -0.002 \\
Statistical tests & & & & \\
R $^{2}$ & 0.473 & 0.747 & 0.836 & 0.503 \\
Adjusted R & 0.431 & 0.672 & 0.735 & 0.356 \\
F-statistic & $11.260^{*}$ & $9.997 *$ & $8.214 *$ & $3.427^{*}$ \\
Diagnostic tests & & & & \\
JB test & $3.397(0.182)$ & $0.193(0.907)$ & $0.982(0.611)$ & $10.275(0.005)$ \\
LM test & $2.230(0.112)$ & $0.872(0.430)$ & $1.421(0.312)$ & $0.433(0.653)$ \\
Heteroskedasticity test & $0.676(0.711)$ & $0.425(0.895)$ & $1.201(0.388)$ & $0.339(0.942)$ \\
Ramsey RESET t-test & $0.215(0.829)$ & $1.786(0.085)$ & $1.316(0.229)$ & $0.415(0.655)$ \\
CUSUM & OK & OK & OK & OK \\
SQCUSUM & OK & ---- & OK & OK \\
\hline
\end{tabular}

*shows $1 \%$ significance level

${ }^{a}$ OLS estimates. CAS shows total registered cases, DTH shows total death, RECOV shows total recovered, CFRD1 shows case fatality ratio concerning death to total cases, CFRD2 shows case fatality ratio concerning death to recovered cases, and LPI shows logistics performance index
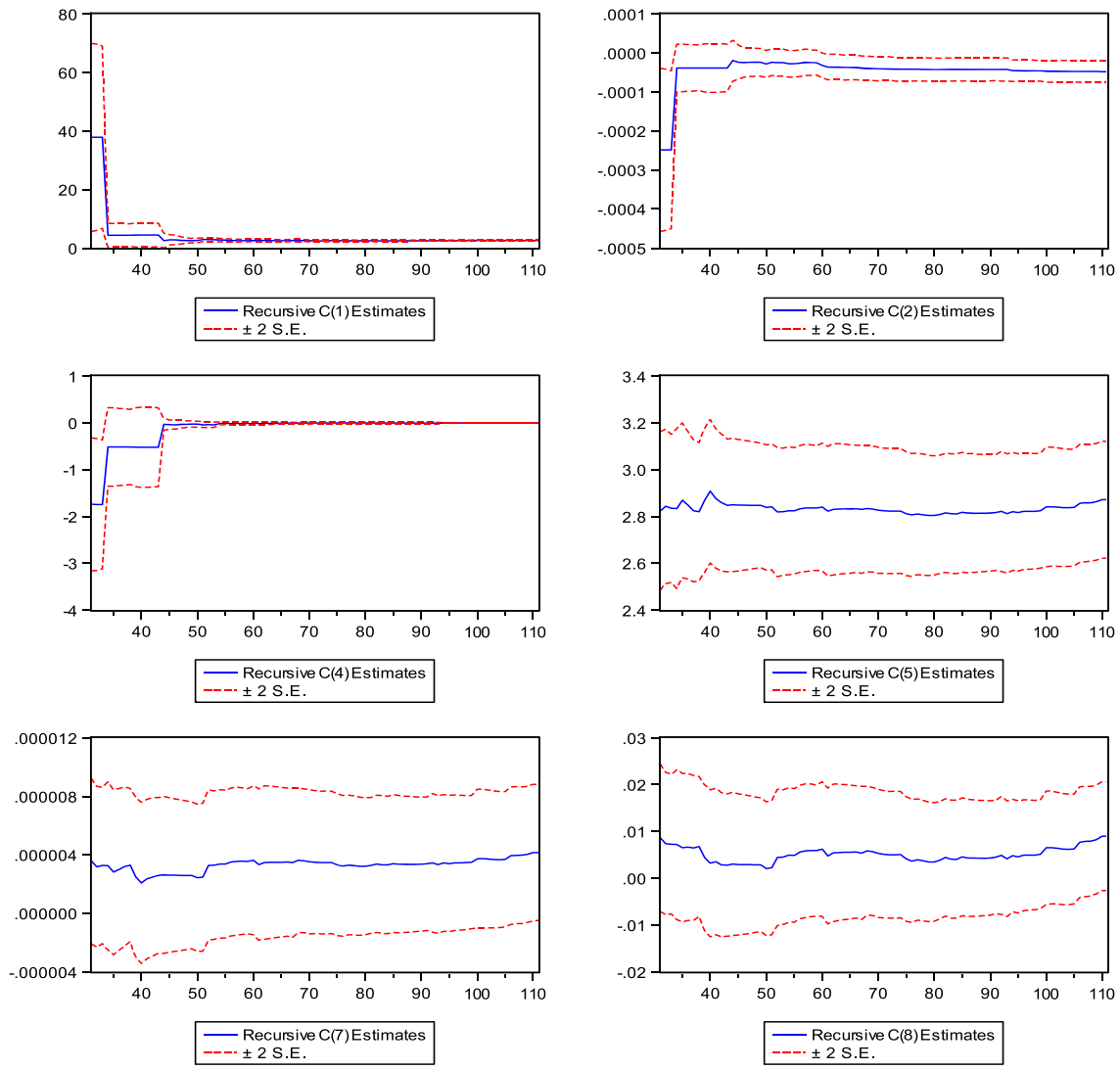

Fig. 4 Recursive coefficients for the overall panel (N=111 countries). Source: Author's estimates
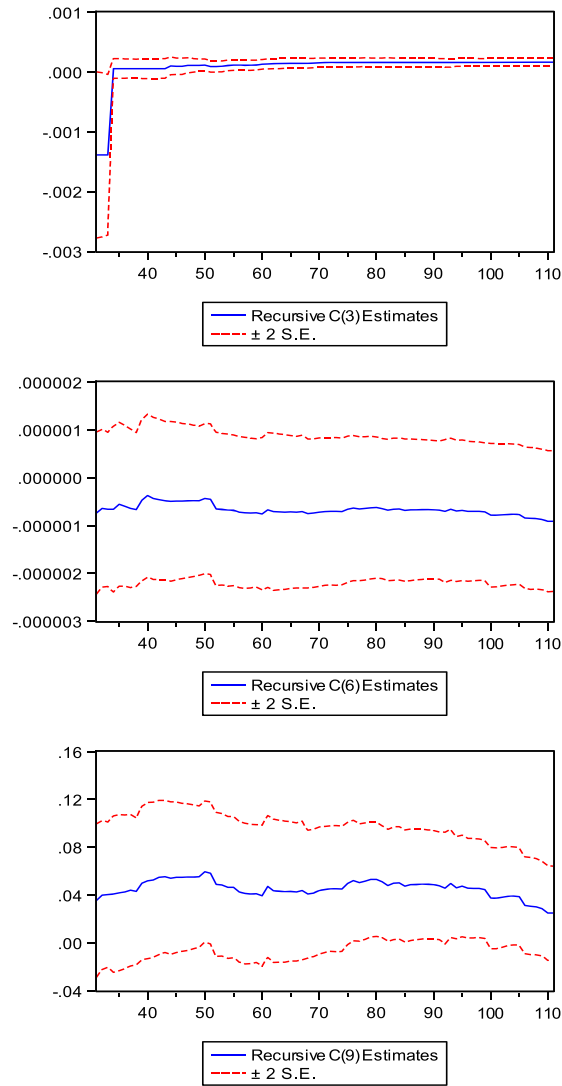
Table 5 Impulse response of LPI for the overall panel $(\mathrm{N}=111$ countries)

\begin{tabular}{lllllll}
\hline Months & LPI & CAS & DTH & RECOV & CFRD1 & CFRD2 \\
\hline June & 0.104 & -0.033 & -0.050 & -0.093 & -0.047 & -0.004 \\
July & 0.031 & -0.051 & -0.065 & -0.031 & -0.023 & 0.034 \\
August & 0.016 & -0.0002 & -0.039 & 0.024 & 0.031 & 0.021 \\
September & 0.016 & 0.008 & -0.015 & 0.050 & 0.015 & 0.013 \\
October & 0.024 & 0.019 & -0.021 & 0.037 & -0.0009 & 0.020 \\
November & 0.029 & 0.008 & -0.017 & 0.027 & -0.004 & 0.014 \\
December & 0.029 & 0.008 & -0.018 & 0.017 & -0.002 & 0.012 \\
January & 0.023 & 0.003 & -0.014 & 0.014 & -0.002 & 0.009 \\
February & 0.019 & 0.004 & -0.013 & 0.012 & -0.001 & 0.008 \\
\hline
\end{tabular}

CAS shows total registered cases, DTH shows total death, RECOV shows total recovered, CFRD1 shows case fatality ratio concerning death to total cases, CFRD2 shows case fatality ratio concerning death to recovered cases, and LPI shows logistics performance index

cases will support to improve supply chain activities from August 2020 onward. The results show some significant variations in the COVID-19 cases that will influence the logistics performance index over time.

Table 6 shows the VDA estimates of LPI and it is found that total coronavirus recovered cases will largely be influenced by supply chain process, followed by death toll, total registered cases, and the proportion of death to registered cases, while the least influenced will be the proportion of death to recovered cases on logistics supply since August 2020 onward.

Table 6 Variance decomposition analysis of LPI for the overall panel ( $\mathrm{N}=111$ countries $)$

\begin{tabular}{llllllll}
\hline Months & SE. & LPI & CAS & DTH & RECOV & CFRD1 & CFRD2 \\
\hline June & 0.534 & 94.028 & 0.392 & 0.881 & 3.035 & 0.793 & 0.006 \\
July & 0.545 & 90.612 & 1.263 & 2.306 & 3.248 & 0.953 & 0.409 \\
August & 0.554 & 87.810 & 1.223 & 2.748 & 3.344 & 1.246 & 0.549 \\
September & 0.561 & 85.458 & 1.213 & 2.750 & 4.069 & 1.289 & 0.592 \\
October & 0.568 & 83.745 & 1.303 & 2.835 & 4.414 & 1.260 & 0.709 \\
November & 0.571 & 82.956 & 1.309 & 2.890 & 4.586 & 1.250 & 0.768 \\
December & 0.574 & 82.428 & 1.317 & 2.961 & 4.638 & 1.241 & 0.805 \\
January & 0.576 & 82.100 & 1.313 & 3.003 & 4.676 & 1.235 & 0.827 \\
February & 0.577 & 81.826 & 1.312 & 3.042 & 4.698 & 1.230 & 0.846 \\
\hline
\end{tabular}

CAS shows total registered cases, DTH shows total death, RECOV shows total recovered, CFRD1 shows case fatality ratio concerning death to total cases, CFRD2 shows case fatality ratio concerning death to recovered cases, and LPI shows logistics performance index

\section{Discussion of findings}

The series of questions regarding pandemic recessions, carbon emissions, and supply chain disruptions were asked from the academicians that hold a Ph.D. degree and have a diverse background on the stated topic. The main questions and their answers are reported in Table 7 for ready reference.

The qualitative assessment confirmed the statistical results of the study. The need for sustainable logistics policies improves air quality while improving the general public's immune system that is likely less affected by the coronavirus. Table 8 shows the empirical estimates of logistics performance and carbon damages ${ }^{1}$ (denoted by $\mathrm{CO} 2, \%$ of GNI) in a panel of 111 countries.

The results show that case fatality ratios have a differential impact on the logistics performance index, as CFRD1 has a direct relationship while CFRD2 have an indirect relationship with the LPI. The result implies that death to COVID-19 cases increases medical logistics supplies, which is imperative for achieving sustainable healthcare agenda across countries. The impact of carbon damages on LPI is negative, which confirmed that countries restrict unstainable logistic activities and move towards clean and green logistics performance on a large scale. The greater needs to make strict environmental regulations and improve logistics green activities are desirable for achieving the healthcare sustainability agenda worldwide (Yu et al. 2021; Safa et al. 2021; Chowdhury et al. 2021).

\section{Conclusions}

The logistics supply chain is desirable to minimize socioeconomic and environmental issues about the emergence of the COVID-19 pandemic. The study identifies different COVID-19 factors that negatively affect the valuable supply chain process across the globe. The results show that the emergence of the COVID-19 pandemic mainly disrupts the valuable supply chain process that needs unified global policies to ensure a free flow of the logistics supply chain. The increasing number of coronavirus patients and death tolls obstruct the global supply chain process. In contrast, an increase in the number of coronavirus recovery cases liberalizes economic policies and allows industries and businesses to work under a constraint environment, which begins to resume logistics activities worldwide. The forecast estimates show that in June to August 2020, there is a likelihood to increase more coronavirus patients and subsequently increases death toll; however, since September 2020, the high recovery rates and lower new cases embark logistics activities worldwide.

\footnotetext{
${ }^{1}$ Data is taken from World Bank (2020)
} 
Table 7 Qualitative academic assessment regarding carbon emissions, logistics supply chain, and COVID-19 pandemic recession

\begin{tabular}{ll}
\hline $\begin{array}{l}\text { Question } \\
\text { numbers }\end{array}$ & Statements \\
\hline Q.1. & $\begin{array}{l}\text { Would you like to tell us } \\
\text { about the vulnerability of } \\
\text { the COVID-19 pandemic } \\
\text { regarding disruption in the } \\
\text { logistics supply chain and } \\
\text { environmental degrada- } \\
\text { tion? }\end{array}$
\end{tabular}

Answers

Well, the answer is very straight forward. During the COVID-19 pandemic, the global environmental quality is partially improved due to the closure of industries and low traffic on the roads because of strict or smart lockdowns. However, the environmental sustainability agenda could not be achieved in the long-run; once the pandemic recession will over, and industries will again get momentum, traffic volume will increase. On the other hand, the logistics supply, especially medical supply and food supply, was severely disrupted due to travel and transportation restrictions. Hence, it creates many socio-economic issues that need to be resolved through smart planning strategies.

Q.2. Do you think an increase in the number of coronavirus registered cases and death tolls disrupts the sustainable supply chain process?

Q.3. Do you think an increased case fatality ratio would lead the global world more in depression?

Q.4. Do you think if the global world successfully provided coronavirus vaccine to the general public, it would turn the economy out of recession?

Yes, an increase in the number of COVID cases and its associated deaths lead to strict lockdown and closure of industries, which cause more significant disruptions in the inventory management and supply chain process. The need to digitalize information channels and supply process would be helpful to restore logistics operations.

Yes, as the number count down increases, the global economic activities would swing to more recession, and financial activities would mainly affect, which ultimately affects the overall economic

The problem may arise at an early stage when the few countries would get the vaccine while the rest would be waiting in line, so that time, we need to get
Table 7 (continued)

\begin{tabular}{|c|c|c|}
\hline $\begin{array}{l}\text { Question } \\
\text { numbers }\end{array}$ & Statements & Answers \\
\hline & & $\begin{array}{l}\text { COVID-19 and follow the } \\
\text { strict SOPs designed by the } \\
\text { WHO to prevent it from } \\
\text { the pandemic. }\end{array}$ \\
\hline Q.5. & $\begin{array}{l}\text { Finally, we would be happy } \\
\text { to see your views regarding } \\
\text { policies and strategies to } \\
\text { improve sustainable } \\
\text { logistics supply and } \\
\text { minimize the spread of the } \\
\text { COVID-19 pandemic. }\end{array}$ & $\begin{array}{l}\text { Well, logistics supply should } \\
\text { be smoothly performing } \\
\text { during the pandemic } \\
\text { recession. It would help } \\
\text { ensure a free flow of } \\
\text { medical equipment and } \\
\text { life-saving drugs and en- } \\
\text { sure food availability, re- } \\
\text { ducing the incidence of } \\
\text { newly infected cases glob- } \\
\text { ally. Further, logistics op- } \\
\text { erations should be envi- } \\
\text { ronmentally friendly. The } \\
\text { use of renewable fuels in } \\
\text { transport logistics would } \\
\text { help to improve environ- } \\
\text { mental quality indicators. } \\
\text { A healthy environment } \\
\text { improves the immune sys- } \\
\text { tem of the general public } \\
\text { that helps to prevent it from } \\
\text { coronavirus. }\end{array}$ \\
\hline
\end{tabular}
progression worldwide. more precautionary measures related to

\section{Policy recommendations}

The following policy implications are desirable to contain coronavirus cases and improve global logistics activities, i.e.:

Table 8 Robust least squares regression estimates

Dependent variable: LPI

\begin{tabular}{lllll}
\hline Variable & Coefficient & Std. error & $\begin{array}{l}\text { z- } \\
\text { statistic }\end{array}$ & Prob. \\
\hline CFRD1 & 0.071 & 0.017 & 4.035 & 0.000 \\
CFRD2 & -0.005 & 0.003 & -1.884 & 0.059 \\
CO2 & -0.080 & 0.043 & -1.835 & 0.066 \\
Constant & 2.918 & 0.117 & 24.90 & 0.000 \\
Robust statistics & & & \\
$\mathrm{R}^{2}$ & 0.191 & Adjusted $\mathrm{R}^{2}$ & & 0.167 \\
Rw & 0.247 & Adjust $\mathrm{Rw}^{2}$ & & 0.247 \\
$\mathrm{AIC}$ & 107.306 & SIC & & 118.806 \\
\hline
\end{tabular}

CFRD1 shows case fatality ratio concerning death to total cases, CFRD2 shows case fatality ratio concerning death to recovered cases, $\mathrm{CO} 2$ shows carbon damages, and LPI shows logistics performance index 
i) The global economies should provide personal and protective items to the healthcare professionals fighting as frontline soldiers from the coronavirus pandemic. There is a need to ensure the valuable healthcare supply chain for providing medical equipment and other instruments without any significant delays.

ii) The efficient supply chain process is desirable that can be changed according to the given situation. The unified global policies should be framed to free healthcare logistics activities worldwide.

iii) The emphasis on quality and essential productions should keep moving under precautionary restrictions to ensure a free flow of logistics supply that supports businesses to sustain in a given scenario.

iv) The smart lockdown, massive awareness about the deadly pandemic, and adoption of necessary prevention measures would be helpful to restrain coronavirus plague and support to the business-related activities to keep increasing their momentum of production and consumption in order to utilize logistics operations effectively.

v) The need to explore further dimensions of valuable supply chain process would help improve logistics operations worldwide.

It is quite apparent that global carbon emissions substantially decrease due to shutdown manufacturing industries that lead to serve the cause of employees' downsizing, increase mental illness, severe financial crisis, and loss of production and consumption. The logistics activities were affected during the COVID-19 pandemic, which needs to come back through digitalize manufacturing. Food supply provision is the ultimate challenge in unprecedented times, not limited to food shortages and production. Simultaneously, the greater need to maintain the COVID-19-associated SOPs in the retail stores is considered the most significant challenge to contain pandemic recession. In this regard, the sustainable food logistics supply is the ultimate option to minimize coronavirus pandemic spread through online purchase decisions. The need for considering health protocols and autonomation is desirable to sustain logistics activities. The role of information technologies in using logistics operations to digitize their working channels would help move forward for long-term growth and contain the COVID-19 pandemic across countries.

The study is limited to the three factors of coronavirus pandemic used in this study to estimate case fatality ratio and recovered ratio. Simultaneously, there is a high need to extend it with some other factors, including population density, testing labs, financial indicators, and information channels that would give more policy insights to formulate effective long-term policies. Furthermore, the study only focused on sustainable logistics supply while extending it with the medical supply chain, food supply chain, and transport supply chain to assess the economic shocks of COVID-19 on logistics activities across countries. These policies suggested a way to move forward under a constraint environment, which we may use to defeat coronavirus through unified global healthcare supply chain policies.

Acknowledgements Researchers Supporting Project number (RSP2021/87), King Saud University, Riyadh, Saudi Arabia.

Author contribution MKA: conceptualization, methodology, and writing-reviewing and editing. MAK: software, formal analysis, and methodology. AAN: supervision, resources, and software. MMQA: resources, visualization, and formal analysis. KZ: software, formal analysis, and resources. AK: data curation and validation.

Availability of data and materials The data is freely available at Worldometer (2020) at https://www.worldometers.info/coronavirus/ and World Development Indicators published by World Bank (2020) at https://databank.worldbank.org/source/world-development-indicators.

\section{Declarations}

Ethics approval Not applicable.

Consent to participate All authors equally participated in the study.

Consent for publication All authors allow the publication of the paper.

Competing interests The authors declare no competing interests.

\section{References}

Agrawal S., Jamwal A., Gupta S. (2020). Effect of COVID-19 on the Indian economy and supply chain. Preprints, doi: 10.20944/ preprints202005.0148.v1.

Ahmed, N., Shakoor, M., Vohra, F., Abduljabbar, T., Mariam, Q., \& Rehman, M. A. (2020). Knowledge, awareness and practice of health care professionals amid SARS-CoV-2, corona virus disease outbreak. Pakistan Journal of Medical Sciences, (COVID19-S4), S49, https://doi.org/10.12669/pjms.36.COVID19-S4.2704, 36, S49, S56.

Al-Mansour JF, Al-Ajmi SA (2020) Coronavirus 'COVID-19'-supply chain disruption and implications for strategy, economy, and management. The Journal of Asian Finance, Economics, and Business 7(9):659-672

Anser MK, Yousaf Z, Khan MA, Nassani AA, Alotaibi SM, Abro MMQ et al (2020a) Does communicable diseases (including COVID-19) may increase global poverty risk? A cloud on the horizon. Environ Res 187:109668

Anser MK, Islam T, Khan MA, Zaman K, Nassani AA, Askar SE et al (2020b) Identifying the potential causes, consequences, and prevention of communicable diseases (including COVID-19). Biomed Res Int:8894006. https://doi.org/10.1155/2020/8894006

Anser MK, Yousaf Z, Khan MA, Sheikh AZ, Nassani AA, Abro MMQ, Zaman K (2020c) Communicable diseases (including COVID19)_induced global depression: caused by inadequate healthcare expenditures, population density, and mass panic. Front Public Health 8:398. https://doi.org/10.3389/fpubh.2020.00398 
Bandyopadhyay R. (2020) Migrant labour, informal economy, and logistics sector in a Covid-19 World. Borders of an Epidemic, pp. 31-41, Mahanirban Calcutta Research Group, Kolkata.

Chowdhury P, Paul SK, Kaisar S, Moktadir MA (2021) COVID-19 pandemic related supply chain studies: a systematic review. Logistics and Transportation Review, Transportation Research Part E, p 102271

El Baz J, Ruel S (2021) Can supply chain risk management practices mitigate the disruption impacts on supply chains' resilience and robustness? Evidence from an empirical survey in a COVID-19 outbreak era. Int J Prod Econ 233:107972

Fong Y, Huang Y, Gilbert PB, Permar SR (2017) chngpt: threshold regression model estimation and inference. BMC bioinformatics 18(1):1-7

Gagliano A, Villani PG, Manelli A, Paglia S, Bisagni PA, Perotti GM et al (2020) COVID-19 epidemic in the middle province of Northern Italy: impact, logistics, and strategy in the first line hospital. Disaster medicine and public health preparedness 14(3):372-376

Galaitsi SE, Keisler JM, Trump BD, Linkov I (2021) The need to reconcile concepts that characterize systems facing threats. Risk Anal 41(1):3-15

Glauber JOSE PH., Laborde DAVID., Martin WILL, Vos, R. (2020). COVID-19: trade restrictions are worst possible response to safeguard food security. International Food Policy Research Institute, 27. Online available at: https://www.global-solutions-initiative.org/ wp-content/uploads/2020/04/IFPRI-COVID-19-Trade-restrictionsand-the-stability-of-food-supplies_315_2.pdf(accessed on 4th June, 2020).

Goel RK, Saunoris W, Goel SS (2020). Supply chain reliability and international economic growth: impacts of disruptions like COVID-19. Online available at: https://papers.ssrn.com/sol3/ papers.cfm?abstract id $=3603829$ (accessed on $2^{\text {nd }}$ July 2020).

Golan MS, Jernegan LH, Linkov I (2020) Trends and applications of resilience analytics in supply chain modeling: systematic literature review in the context of the COVID-19 pandemic. Environment Systems and Decisions 40:222-243

Goodell JW (2020) COVID-19 and finance: agendas for future research. Financ Res Lett 35:101512. https://doi.org/10.1016/j.frl.2020. 101512

Greenberg N, Docherty M, Gnanapragasam S, Wessely S (2020) Managing mental health challenges faced by healthcare workers during covid-19 pandemic. bmj 368. https://doi.org/10.1136/bmj. m1211

He F, Deng Y, Li W (2020) Coronavirus disease 2019: what we know? J Med Virol 92(7):719-725

Ivanov D (2020a) Viable supply chain model: integrating agility, resilience and sustainability perspectives - lessons from and thinking beyond the COVID-19 pandemic. Ann Oper Res. https://doi.org/ $10.1007 / \mathrm{s} 10479-020-03640-6$

Ivanov D (2020b) Predicting the impacts of epidemic outbreaks on global supply chains: a simulation-based analysis on the coronavirus outbreak (COVID-19/SARS-CoV-2) case. Transportation Research Part E: Logistics and Transportation Review 136:101922

Ivanov D, Dolgui A (2020) Viability of intertwined supply networks: extending the supply chain resilience angles towards survivability. A position paper motivated by COVID-19 outbreak. Int J Prod Res 58(10):2904-2915

Iyengar KP, Vaishya R, Bahl S, Vaish A (2020) Impact of the coronavirus pandemic on the supply chain in healthcare. Br J Health Care Manag 26(6):1-4

Kawohl W, Nordt C (2020) COVID-19, unemployment, and suicide. Lancet Psychiatry 7(5):389-390

Lai CC, Shih TP, Ko WC, Tang HJ, Hsueh PR (2020) Severe acute respiratory syndrome coronavirus 2 (SARS-CoV-2) and corona virus disease-2019 (COVID-19): the epidemic and the challenges. Int J Antimicrob Agents 55(3):105924
Larrañeta E, Dominguez-Robles J, Lamprou DA (2020) Additive manufacturing can assist in the fight against COVID-19 and other pandemics and impact on the global supply chain. 3D. Printing and Additive Manufacturing 7(3):100-103

Linkov I, Carluccio S, Pritchard O, Bhreasail ÁN, Galaitsi S, Sarkis J, Keisler JM (2020) The case for value chain resilience. Manag Res Rev 43(12). https://doi.org/10.1108/MRR-08-2019-0353

Liu Y, Lee JM, Lee C (2020) The challenges and opportunities of a global health crisis: the management and business implications of COVID19 from an Asian perspective. Asian Bus Manag 19:277-297

Loske D (2020) The impact of COVID-19 on transport volume and freight capacity dynamics: an empirical analysis in German food retail logistics. Transportation Research Interdisciplinary Perspectives 6:100165

Mahajan K, Tomar S (2020). Here today, gone tomorrow: COVID-19 and supply chain disruption. Online available at: https://papers.ssrn. com/sol3/papers.cfm?abstract id $=3596720$ (accessed on $2^{\text {nd }}$ July 2020).

Malhotra D (2020). Managing agricultural supply chains in COVID-19 lockdown. Online available at: https://papers.ssrn.com/sol3/papers. cfm?abstract_id $=3602574$ (accessed on $2^{\text {nd }}$ July 2020).

McMaster M, Nettleton C, Tom C, Xu B, Cao C, Qiao P (2020) Risk management: rethinking fashion supply chain management for multinational corporations in light of the COVID-19 outbreak. J Risk Financ Manag 13(8):173. https://doi.org/10.3390/jrfm13080173

Nandi ML, Nandi S, Moya H, Kaynak H (2020) Blockchain technologyenabled supply chain systems and supply chain performance: a resource-based view. Int J Supply Chain Manag 25(6):841-862

Nicola M, Alsafi Z, Sohrabi C, Kerwan A, Al-Jabir A, Iosifidis C et al (2020) The socio-economic implications of the coronavirus and COVID-19 pandemic: a review. Int J Surg 78:185-193

Novak JI, Loy J (2020) A critical review of initial 3D printed products responding to COVID-19 health and supply chain challenges. Emerald Open Research 2(24):24

Purcell LN, Charles AG (2020) An Invited Commentary on "World Health Organization declares global emergency: a review of the 2019 novel Coronavirus (COVID-19)": emergency or new reality? International Journal of Surgery (London, England) 76:111. https:// doi.org/10.1016/j.ijsu.2020.03.002

Queiroz MM, Ivanov D, Dolgui A, Wamba SF (2020) Impacts of epidemic outbreaks on supply chains: mapping a research agenda amid the COVID-19 pandemic through a structured literature review. Ann Oper Res. https://doi.org/10.1007/s10479-020-03685-7

Rosenbaum L (2020) Facing Covid-19 in Italy - ethics, logistics, and therapeutics on the epidemic's front line. N Engl J Med 382(20): $1873-1875$

Rowan NJ, Laffey JG (2020) Challenges and solutions for addressing critical shortage of supply chain for personal and protective equipment (PPE) arising from Coronavirus disease (COVID19) pandemic-Case study from the Republic of Ireland. Sci Total Environ 725:138532

Safa M, Sharma N, Zelbst P (2021). Information-driven supply chain during a catastrophic event: COVID-19 pandemic. Journal of Operations and Strategic Planning, 2516600X20987354.

Stephenson J (2020). FDA warns coronavirus outbreak may disrupt supply of critical medical products. In JAMA Health Forum (Vol. 1, No. 2, pp. e200222-e200222). American Medical Association.

Villalobos-Arias M (2020). Estimation of population infected by Covid19 using regression generalized logistics and optimization heuristics. arXiv preprint arXiv:2004.01207.

$\mathrm{Vu} \mathrm{HM}$ (2020) A review of dynamic capabilities, innovation capabilities, entrepreneurial capabilities and their consequences. The Journal of Asian Finance, Economics and Business (JAFEB) 7(8):485-494

Wong CW, Lirn TC, Yang CC, Shang KC (2020) Supply chain and external conditions under which supply chain resilience pays: an 
organizational information processing theorization. Int J Prod Econ 226:107610

World Bank (2020) World Development Indicators. World Bank, Washington D.C

World Health Organization. (2020). Rational use of personal protective equipment for coronavirus disease (COVID-19) and considerations during severe shortages: interim guidance, 6 April 2020 (No. WHO/ 2019-nCov/IPC_PPE use/2020.3). World Health Organization.

Worldometer (2020). COVID-19 coronavirus pandemic. Online available at: https://www.worldometers.info/coronavirus/ (accessed on $29^{\text {th }}$ May, 2020).

Yang KC, Torres-Lugo C, Menczer F (2020) Prevalence of lowcredibility information on twitter during the covid-19 outbreak. arXiv preprint arXiv:2004.14484
Yu H, Sun X, Solvang WD, Zhao X (2020) Reverse logistics network design for effective management of medical waste in epidemic outbreaks: insights from the coronavirus disease 2019 (COVID-19) outbreak in Wuhan (China). Int J Environ Res Public Health 17(5):1770. https://doi.org/10.3390/ijerph17051770

Yu Z, Razzaq A, Rehman A, Shah A, Jameel K, Mor RS (2021) Disruption in global supply chain and socio-economic shocks: a lesson from COVID-19 for sustainable production and consumption. Oper Manag Res. https://doi.org/10.1007/s12063-021-00179-y

Publisher's note Springer Nature remains neutral with regard to jurisdictional claims in published maps and institutional affiliations. 